\title{
Characterization of a pneumococcal meningitis mouse model
}

\author{
Barry Mook-Kanamori ${ }^{1 \dagger}$, Madelijn Geldhoff ${ }^{1 \dagger}$, Dirk Troost ${ }^{2}$, Tom van der Poll ${ }^{3}$ and Diederik van de Beek ${ }^{1,4^{*}}$
}

\begin{abstract}
Background: S. pneumoniae is the most common causative agent of meningitis, and is associated with high morbidity and mortality. We aimed to develop an integrated and representative pneumococcal meningitis mouse model resembling the human situation.

Methods: Adult mice (C57BL/6) were inoculated in the cisterna magna with increasing doses of S. pneumoniae serotype 3 colony forming units (CFU; $n=24,10^{4}, 10^{5}, 10^{6}$ and $10^{7} \mathrm{CFU}$ ) and survival studies were performed. Cerebrospinal fluid (CSF), brain, blood, spleen, and lungs were collected. Subsequently, mice were inoculated with $10^{4}$ CFU S. pneumoniae serotype 3 and sacrificed at $6(n=6)$ and 30 hours $(n=6)$. Outcome parameters were bacterial outgrowth, clinical score, and cytokine and chemokine levels (using Luminex ${ }^{\circledR}$ ) in CSF, blood and brain. Meningeal inflammation, neutrophil infiltration, parenchymal and subarachnoidal hemorrhages, microglial activation and hippocampal apoptosis were assessed in histopathological studies.

Results: Lower doses of bacteria delayed onset of illness and time of death (median survival CFU 104, 56 hrs; $10^{5}$, $38 \mathrm{hrs}, 10^{6}, 28 \mathrm{hrs} .10^{7}, 24 \mathrm{hrs}$ ). Bacterial titers in brain and CSF were similar in all mice at the end-stage of disease independent of inoculation dose, though bacterial outgrowth in the systemic compartment was less at lower inoculation doses. At 30 hours after inoculation with $10^{4}$ CFU of S. pneumoniae, blood levels of KC, IL6, MIP-2 and IFN- $\gamma$ were elevated, as were brain homogenate levels of KC, MIP-2, IL-6, IL-1 $\beta$ and RANTES. Brain histology uniformly showed meningeal inflammation at 6 hours, and, neutrophil infiltration, microglial activation, and hippocampal apoptosis at 30 hours. Parenchymal and subarachnoidal and cortical hemorrhages were seen in 5 of 6 and 3 of 6 mice at 6 and 30 hours, respectively.
\end{abstract}

Conclusion: We have developed and validated a murine model of pneumococcal meningitis.

Keywords: Meningitis, Critical care, Neurology, Animal model, Infectious diseases

\section{Background}

Bacterial meningitis is a life threatening infectious disease of the central nervous system (CNS). The annual incidence is estimated to be up to 2.6 to 6.0 cases per 100000 in Europe and may be up to ten times higher in developing countries $[1,2]$. The most common pathogen beyond the neonatal period is Streptococcus pneumoniae [1,3], causing $70 \%$ of cases. Despite advances in medical care, mortality from pneumococcal meningitis remains between $16 \%$ and $37 \%$ and neurological sequelae affect $30-52 \%$ of

\footnotetext{
* Correspondence: d.vandeBeek@amc.uva.nl

† Contributed equally

'Department of Neurology, Center of Infection and Immunity Amsterdam

(CINIMA), Academic Medical Center, Amsterdam, the Netherlands

Full list of author information is available at the end of the article
}

survivors [4-6]. There is a continuing need for the development of new treatment strategies.

Complications associated with pneumococcal meningitis include cerebral infarction, hemorrhages, motor and sensory deficit, seizures, memory and learning impairments, and hearing loss $[2,7,8]$. Autopsy studies of patients who died following pneumococcal meningitis revealed cerebral edema, cerebral infarctions and hemorrhages, apoptosis and necrosis of the hippocampal dentate gyrus [9-11]. Many of these pathological features have been reproduced in animal models, which provide the setting for novel drug development and pathophysiological studies $[12,13]$.

Several murine models have been developed, using intracerebral [14,15], intraperitoneal [16], intravenous [16], intranasal [17] or intracisternal inoculation methods

\section{Biomed Central}


$[18,19]$, and have recently been reviewed [12]. Problems with reproducibility, limited disease progression or iatrogenic structural damage, combined with a need for a single model in which most pathological features seen in human pneumococcal meningitis can be measured, has fueled the development of new animal models. Here we describe the development of an adult mouse model of pneumococcal meningitis in which many of the human pathological features are demonstrated.

\section{Methods}

A clinical isolate of S. pneumoniae serotype 3 was obtained from ATCC (catalog number 6303), and was grown to mid log phase in 4 hours at $37^{\circ} \mathrm{C}$ in ToddHewitt broth supplemented with $0.5 \%$ yeast extract. At an $\mathrm{OD}_{620}$ of 0.8 to 1.0 the S. pneumoniae were centrifuged and washed twice by resuspension in sterile $0.9 \%$ $\mathrm{NaCl}$ and recentrifugation. Finally, the bacteria were resuspended in sterile $\mathrm{NaCl} 0.9 \%$ to yield an approximate concentration of $1 \times 10^{9}$ colony forming units $(\mathrm{CFU}) / \mathrm{ml}$. The exact number of CFUs was subsequently determined for inoculates by serial dilution method and on blood agar plates (overnight at $37^{\circ} \mathrm{C}$ ).

Animal experiments were approved by the Institutional Animal Care and Use Committee of the Academic Medical Center, Amsterdam. To determine the inoculation dose and optimal time points of sacrifice, 24 8-10 week old male C57BL/6 mice (Charles River Laboratories, Germany) received $0.1 \mathrm{mg} / \mathrm{kg}$ s.c. buprenorphine and short-term anesthesia using 1.5-2.0\% isoflurane during inoculation. The mice were divided into 4 groups, each receiving a different concentration of bacterial inoculum $\left(10^{4}, 10^{5}, 10^{6}\right.$ and $10^{7}$ CFU S. pneumoniae per mouse; $\mathrm{n}=$ 6 per dose). Inoculation was conducted by injecting $10 \mu \mathrm{L}$ of bacterial suspension into the cisterna magna using a 32gauge needle. All animals were evaluated directly following inoculation and subsequently at 4-hour intervals. The following scoring was used (Table 1): range: 0-41 pts; each scoring parameter ranging from 0 , corresponding to no deficit, to a variable maximum score. The maximum score was determined by the estimated contribution of the variable to overall health of the mouse): weight loss (0-4 pts), activity (0-4 pts), time to return to upright position (0-6 pts), state of skin/fur (0-3 pts), posture (0-2 pts), eye discharge or protrusion (0-4 pts), respiration rate (0-4 pts), irregular/labored breathing (0-4 pts), epilepsy, limb paresis or ataxia (0-10pts). The clinical course was divided into a pre-symptomatic period (from time of inoculation until clinical score $\leq 10$ ) and symptomatic period (clinical score $>10$ until death/sacrifice). Survival studies were performed and cerebrospinal fluid (CSF), brain, blood, spleen, and lungs were collected post mortem. After determining inoculation dose and time-points of sacrifice, the model was further characterized using 12 additional mice inoculated with $10^{4}$ CFU S. pneumoniae serotype 3 and sacrificed at $6(n=6)$ and 30 hours $(n=6)$.

Bacterial titers were determined in samples of lung, brain, and spleen (diluted 1:4 in sterile $\mathrm{NaCl} 0.9 \%$ and homogenized). Blood was heparinized in a 1:4 dilution and CSF was diluted 1:100 in sterile $\mathrm{NaCl} 0.9 \%$. All bacterial titers were determined by plating serial dilutions on blood agar plates and incubating overnight at $37 \mathrm{C}$.

Cytokine and chemokine measurement were performed on the left cerebral hemisphere diluted 1:4 in sterile $\mathrm{NaCl}$ $0.9 \%$, homogenized and lysed in lysis buffer $(150 \mathrm{mM}$ $\mathrm{NaCl}, 15 \mathrm{mM}$ Tris, $1 \mathrm{mM} \mathrm{MgCl}\left(\mathrm{H}_{2} \mathrm{O}\right)_{6}, 1 \mathrm{mM} \mathrm{CaCl}_{2}$ $\left(\mathrm{H}_{2} \mathrm{O}\right)_{2}, 1 \%$ Triton, AEBSF $4 \mu \mathrm{g} / \mathrm{ml}$, EDTA-NA2 $50 \mu \mathrm{g} / \mathrm{ml}$, pepstatin $10 \mathrm{ng} / \mathrm{ml}$, leupeptin $10 \mathrm{ng} / \mathrm{ml}, \mathrm{pH}$ 7.4). Samples of brain homogenate, serum and CSF were then centrifuged and supernatant stored at $-80 \mathrm{C}$. Cytokine concentrations were determined with luminex ${ }^{\circledR}$ technology using a mouse cytokine and chemokine Bioplex kit (Bio-Rad Laboratories, Veenendaal, The Netherlands).

All mice were perfused by cardiac puncture with PBS prior to harvesting tissue. Histopathology was performed on the right cerebral hemisphere fixed in $4 \%$ paraformaldehyde and paraffin embedded. Coronal $10 \mu \mathrm{m}$ sections of the entire hemisphere were cut for subsequent staining. Hematoxylin and eosin (HE) and Nissl staining were performed to visualize hemorrhages, cortical necrosis, vasculitis and abscess formation. To determine neuronal apoptosis in the dentate gyrus of the hippocampus, four $10 \mu \mathrm{m}$ sections of the anterior, middle and posterior portion of the hippocampus were stained with Caspase-3 antibodies (polyclonal rabbit-anti-mouse, 1:100; Cell Signalling, Danvers, MA). In each section, the total number of caspase-3 positive cells was counted in both the dentate gyrus (DG) and cornu ammonis (CA) regions. Scoring was independently conducted by two investigators. Microglial activation was evaluated by immunohistochemistry using Iba-1 antibody (polyclonal rabbit-anti-mouse, 1:2000; ABcam, Cambridge, UK) staining of frontal lobe $10 \mu \mathrm{m}$ sections. No quantitative analysis was performed.

Comparisons of cytokine levels between groups were calculated using the Mann-Whitney U test. A KruskalWallis one-way ANOVA was used to compare clinical scores of pre-symptomatic and symptomatic periods. Histopathological scores of neuronal apoptosis were compared using Student's $t$-test. For all analyses a p-value < 0.05 was considered significant.

\section{Results}

Mortality occurred in nearly all inoculated mice (Figure 1); one mouse inoculated with $10^{4} \mathrm{CFU}$ survived beyond the study window of 216 hours after inoculation and was sacrificed. The median survival time was dose dependent ( $10^{4}$ CFU, 56 hrs; $10^{5}, 38$ hrs, $10^{6}:, 28$ hrs; $\left.10^{7}, 24 \mathrm{hrs}\right)$. To approximate a physiological setting, we selected $10^{4} \mathrm{CFU}$ 
Table 1 Clinical score parameters, assessed values and weighted scores

\begin{tabular}{|c|c|c|c|}
\hline Parameter & Value & Weighted score & Maximum score \\
\hline \multirow[t]{5}{*}{ Weight loss from baseline } & $5 \%$ & 0 & \\
\hline & $10 \%$ & 1 & \\
\hline & $15 \%$ & 2 & \\
\hline & $20 \%$ & 3 & \\
\hline & $25 \%$ & 4 & 4 \\
\hline \multirow[t]{6}{*}{ Activity } & normal & 0 & \\
\hline & increased/decreased & 1 & \\
\hline & mildely deminished & 1 & \\
\hline & deminished & 2 & \\
\hline & severely deminished & 3 & \\
\hline & coma & 4 & 4 \\
\hline Time to return to upright & normal & 0 & \\
\hline \multirow[t]{3}{*}{ position } & upright $<5 \mathrm{sec}$ & 2 & \\
\hline & upright $<30 \mathrm{sec}$ & 4 & \\
\hline & no turn upright & 6 & 6 \\
\hline \multirow[t]{4}{*}{ Coat } & normal & 0 & \\
\hline & deminished grooming & 1 & \\
\hline & soiled & 1 & \\
\hline & piloerection & 1 & 3 \\
\hline \multirow[t]{3}{*}{ Posture } & normal & 0 & \\
\hline & sligh hunched back & 1 & \\
\hline & sev hunched back & 2 & 2 \\
\hline \multirow[t]{5}{*}{ Eyes } & normal & 0 & \\
\hline & protruding & 1 & \\
\hline & sunken eyes & 1 & \\
\hline & closed eyelids & 1 & \\
\hline & discharge & 1 & 4 \\
\hline \multirow[t]{5}{*}{ Respiration rate (per min) } & $>150$ & 0 & \\
\hline & $<150$ & 1 & \\
\hline & $<100$ & 2 & \\
\hline & $<75$ & 3 & \\
\hline & $<50$ & 4 & 4 \\
\hline \multirow[t]{2}{*}{ Breathing } & irregular & 2 & \\
\hline & laboured & 2 & 4 \\
\hline \multirow[t]{5}{*}{ Neurologic exam } & normal & 0 & \\
\hline & ataxia & 2 & \\
\hline & limb paresis/paralysis & 2 & \\
\hline & epileptic seizure & 2 & \\
\hline & status epilepticus & 6 & 10 \\
\hline Total & & & 41 \\
\hline
\end{tabular}

as the lowest concentration of bacterial inoculum in which most animals would die if left untreated. Furthermore, for future experimentation we chose 30 hours post inoculation as the latest time point for sacrifice, at which all animals were still alive and the natural course of the infection could be followed as long as possible.

Clinical scoring was performed on all mice in the survival study. The average duration of the pre-symptomatic period (clinical score $\leq 10$ ) was dose dependent, and increased approximately 1.5 -fold with each successive 10 -fold increase of bacterial inoculum concentration. The duration of the symptomatic period did not differ significantly between inoculation doses (mean, $11.7 \mathrm{hrs}$, SD 4.8; Table 2).

Bacterial meningitis was confirmed in all 23 mice in the survival study by way of culture of CSF and brain homogenate following death or sacrifice. The average pneumococcal concentration in the CSF and brain homogenates 


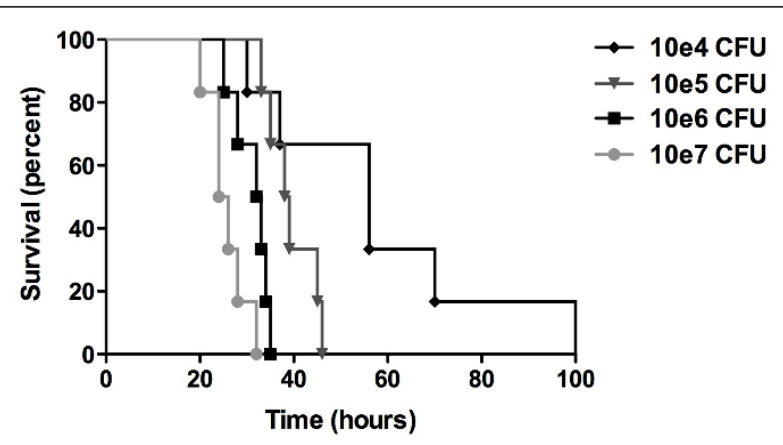

Figure 1 Kaplan-Meier survival curve. Four groups of 6 mice inoculated via direct intracisternal injection with $10^{4}, 10^{5}, 10^{6}$ and $10^{7} \mathrm{CFU}$ of S. pneumoniae/mouse respectively

was $2.0 \times 10^{9} \mathrm{CFU} / \mathrm{ml}$ and $7.9 \times 10^{8} \mathrm{CFU} / \mathrm{ml}$ respectively. Bacterial titers in de CNS compartment (CSF and brain) did not increase with higher inoculation doses (Figure 2). In comparison with the CNS compartment, in the systemic compartment (blood, spleen, lung) bacterial concentrations were much lower (means $1.0 \times 10^{6}, 4.0 \times 10^{5}$ and $2.0 \times 10^{5} \mathrm{CFU} / \mathrm{ml}$, respectively), and an increasing bacterial titer was observed with each successive 10-fold increase of bacterial inoculum concentration.

Mice with pneumococcal meningitis showed increased plasma levels of $\mathrm{KC}$ at 6 hours (Figure 3; median 62 versus $213 \mathrm{pg} / \mathrm{ml}, \mathrm{P}=0.004$ ) and 30 hours (median 62 versus $2031 \mathrm{pg} / \mathrm{ml}, \mathrm{P}<0.0001$ ) compared to saline inoculated mice. Furthermore, at 30 hours IL-6 (median 2 versus 202 $\mathrm{pg} / \mathrm{ml}, \mathrm{P}<0.001$ ), MIP-2 (median 5 versus $63 \mathrm{pg} / \mathrm{ml}, \mathrm{P}=$ $0.002)$ and IFN- $\gamma$ (median 3 versus $16 \mathrm{pg} / \mathrm{ml}, \mathrm{P}=0.002$ ) were elevated in plasma of $S$. pneumoniae compared to sham inoculated mice. IL-1 $\beta$, IL-2, IL-4, IL-10, IL-12p70, IL-17, RANTES, TNF- $\alpha$, IL-18 and IL-33 were not significantly altered in the plasma of mice with pneumococcal meningitis compared to sham controls.

In brain homogenates, mice with pneumococcal meningitis compared to saline inoculated mice showed elevated levels of KC and MIP-2 at both 6 hours (Figure 3; KC median 60 versus $393 \mathrm{pg} / \mathrm{ml}, \mathrm{P}<0.0001$; MIP-2 median 45 versus $159 \mathrm{pg} / \mathrm{ml}, \mathrm{P}=0.003$ ) and 30 hours (KC median 60 versus $18116 \mathrm{pg} / \mathrm{ml}, \mathrm{P}<0.0001$; MIP-2 median 45 versus $10637 \mathrm{pg} / \mathrm{ml}, \mathrm{P}<0.0001$ ) time points. IL-6 (median 20 versus $795 \mathrm{pg} / \mathrm{ml}, \mathrm{P}<0.0001$ ), IL-1 $\beta$ (median 165 versus $939 \mathrm{pg} / \mathrm{ml}, \mathrm{P}=0.014$ ), and RANTES (median 15

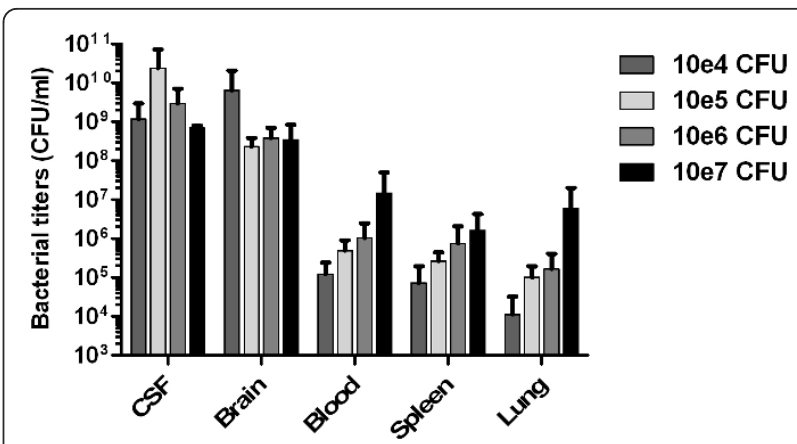

Figure 2 Bacterial outgrowth. Bacterial titers in CSF, brain (central nervous system compartment), and blood, spleen, and lung (systemic compartment) at the end-stage of disease after inoculation with $10^{4}, 10^{5}, 10^{6}$ and $10^{7}$ CFU S. pneumoniae per mouse. Titers are expressed mean CFU/ml +/- S.E.M.

versus $1823 \mathrm{pg} / \mathrm{ml}, \mathrm{P}<0.0001)$ were increased at 30 hours post infection in mice inoculated with pneumococcal meningitis as compared to saline inoculated mice. IL-2, IL-4, IL-10, IL-12p70, IL-17, IFN- $\gamma$, TNF- $\alpha$, IL-18 and IL33 were not altered in brain homogenates of mice with pneumococcal meningitis compared to sham controls. In CSF of mice with pneumococcal meningitis compared to saline inoculated mice, IL-6 (median 26 versus $2772 \mathrm{pg} /$ $\mathrm{ml}, \mathrm{P}=<0.001$ ), $\mathrm{KC}$ (median 84 versus $8369 \mathrm{pg} / \mathrm{ml}, \mathrm{P}=$ 0.002 ), MIP-2 (median 63 versus $5542 \mathrm{pg} / \mathrm{ml}, \mathrm{P}=0.002$ ) and RANTES (median 21 versus $309 \mathrm{pg} / \mathrm{ml}, \mathrm{P}=0.005$ ) are elevated 30 hours post infection.

Histopathology at 6 hours after infection showed high levels of meningeal inflammation in both peripheral and ventricular CSF compartments, but none of the mice had parenchymal lymphocytic infiltration, hemorrhages, microglial activation, or hippocampal apoptosis (Figure 4A). However, 30 hours after inoculation 3 of the 6 mice showed parenchymal lymphocytic infiltration and pockets of bacteria were seen in 2 of 6 mice, located in the perivascular spaces of the penetrating vasculature (Figure $4 \mathrm{~b}$ ). At 30 hours, 5 of 6 mice had one or more parenchymal, mainly cortical, hemorrhages. Three mice demonstrated subarachnoidal hemorrhages. Extensive diffuse microglial activation was observed mice 30 hours after infection and at end stage-stage of disease at all inoculation doses (Figure 4C), although no quantitative analyses were performed. Neuronal apoptosis in the dentate gyrus of the hippocampus was

Table 2 Duration of pre-symptomatic (time from inoculation to clinical score $\leq 10$ ) and symptomatic (time from clinical score $>10$ to death/sacrifice) periods

\begin{tabular}{lccccc}
\hline Inoculation dose (CFU/mouse) & 10e4 & 10e5 & 10e6 & 10e7 & $p$-value \\
\hline Pre-symptomatic period (hrs/st.dev) & $40.7(14.9)$ & $26.1(6.1)$ & $18.7(3.9)$ & $12.0(2.1)$ & 0.001 \\
\hline Symptomatic period (hrs/st.dev) & $9.1(3.2)$ & $13.0(6.3)$ & $10.8(3.6)$ & $13.6(5.3)$ & 0.557 \\
\hline
\end{tabular}

Mean durations of the pre-symptomatic and symptomatic periods (expressed in hours) of the mice of the survival study. Mice were divided into 4 groups and inoculated with 104 (5 mice, 1 mouse was excluded from analysis due to lack of any symptoms due to failed inoculation), 105 (6 mice), 106 (6 mice) and 107 CFU (6 mice) S. pneumoniae per mouse. Comparison of the clinical scores of pre-symptomatic and symptomatic periods was made using a Kruskal- Wallis oneway ANOVA 


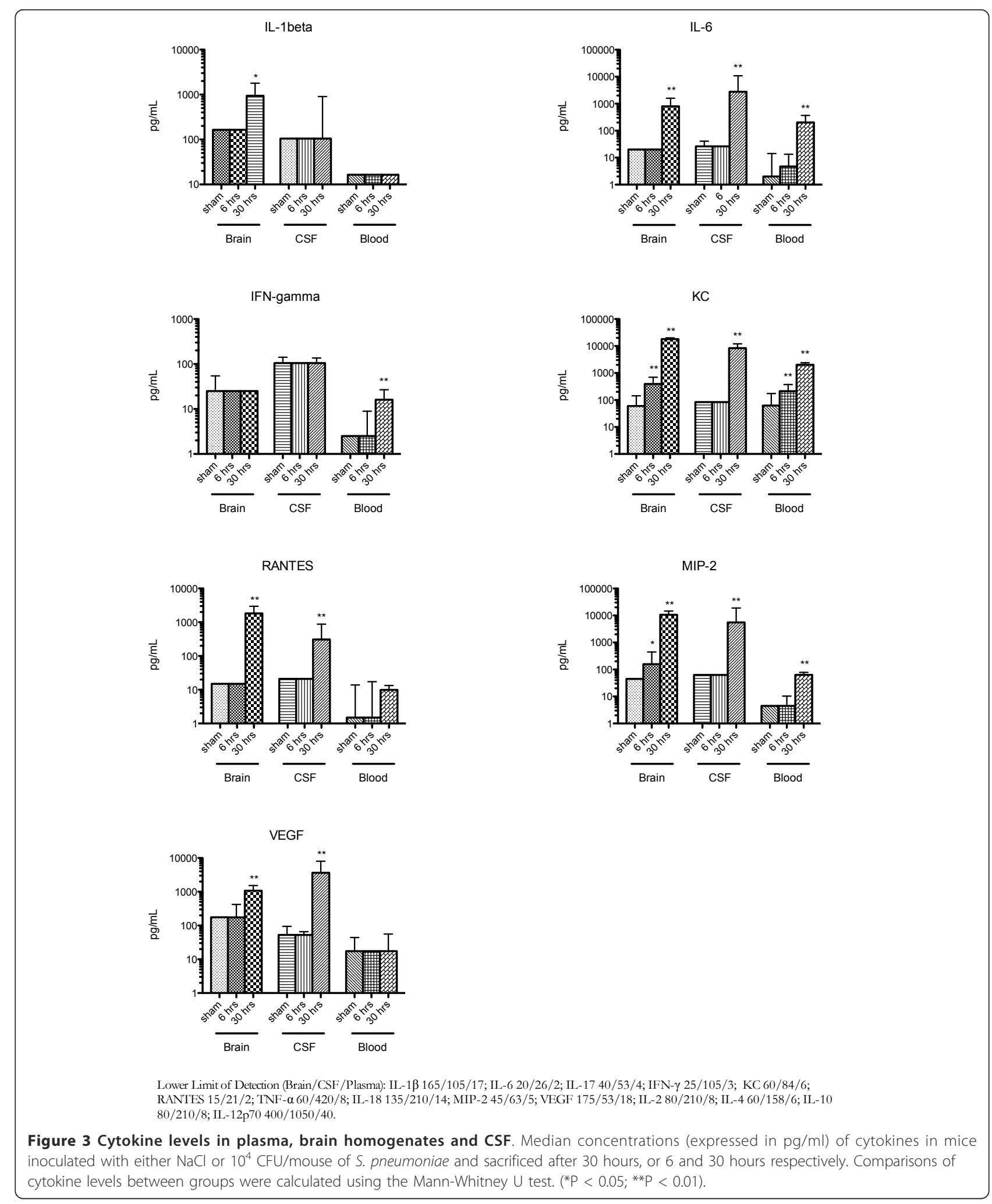




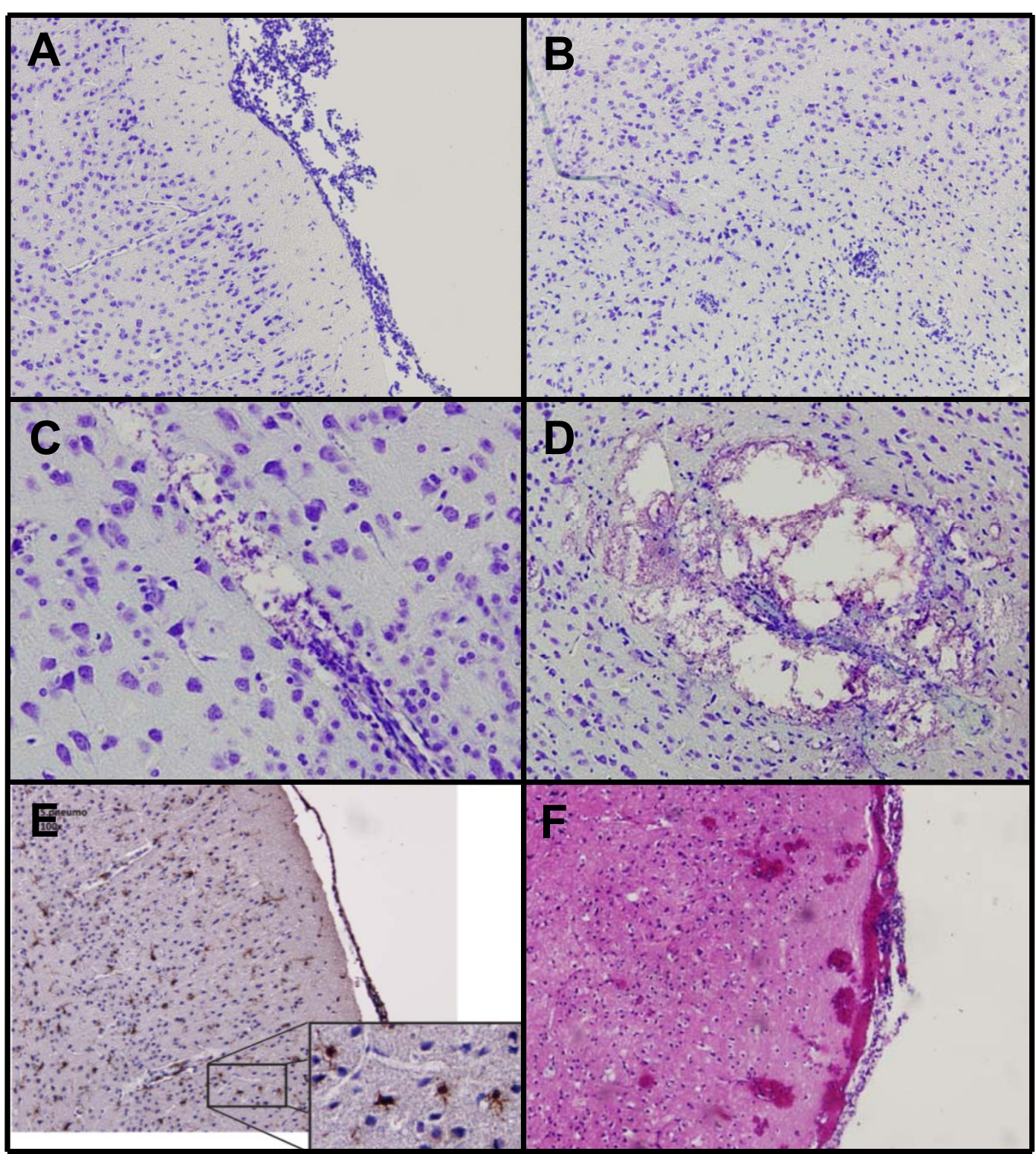

Figure 4 Brain pathology of mice with pneumococcal meningitis. Nissl staining of the cortex of mice infected with S. pneumoniae, showing extensive leptomeningeal inflammatory infiltrate (A; 100x magnification), perivascular lymphocytic cuffing (B; 100x magnification), perivascular lymphocytic infiltration combined with bacterial overgrowth ( $C_{;} 200 \times$ magnification) and further bacterial overgrowth combined with perivascular necrosis (D; 100x magnification). Iba-1 immunohistochemistry revealed microglial activation ( $E_{;}$100x magnification). Hematoxylin and eosin staining showed subarachnoidal and cortical hemorrhages ( $F$; 100× magnification).

scored independently by two investigators with a kappa of 0.75. A significant increase in hippocampus neuronal apoptosis was observed at 30 hours post infection and was significantly higher than saline infected mice ( 0.6 vs. 2.8 cells, $\mathrm{P}<0.001$; Figure 5).

\section{Discussion}

We developed a murine model of pneumococcal meningitis in which the histopathological and inflammatory features as well as observed complications resemble clinical and pathological findings in humans following bacterial meningitis $[1,20]$. The most important features of this model lie in the possibility of combining a relatively low dose of inoculum and long period of disease progression, allowing for a reproducible setting to examine clinical features as well as sufficient time to develop the histopathological features seen in a human setting.

In previous murine models, pneumococcal meningitis was established by either 1) direct bacterial inoculation into the CNS, which generally very short survival times 


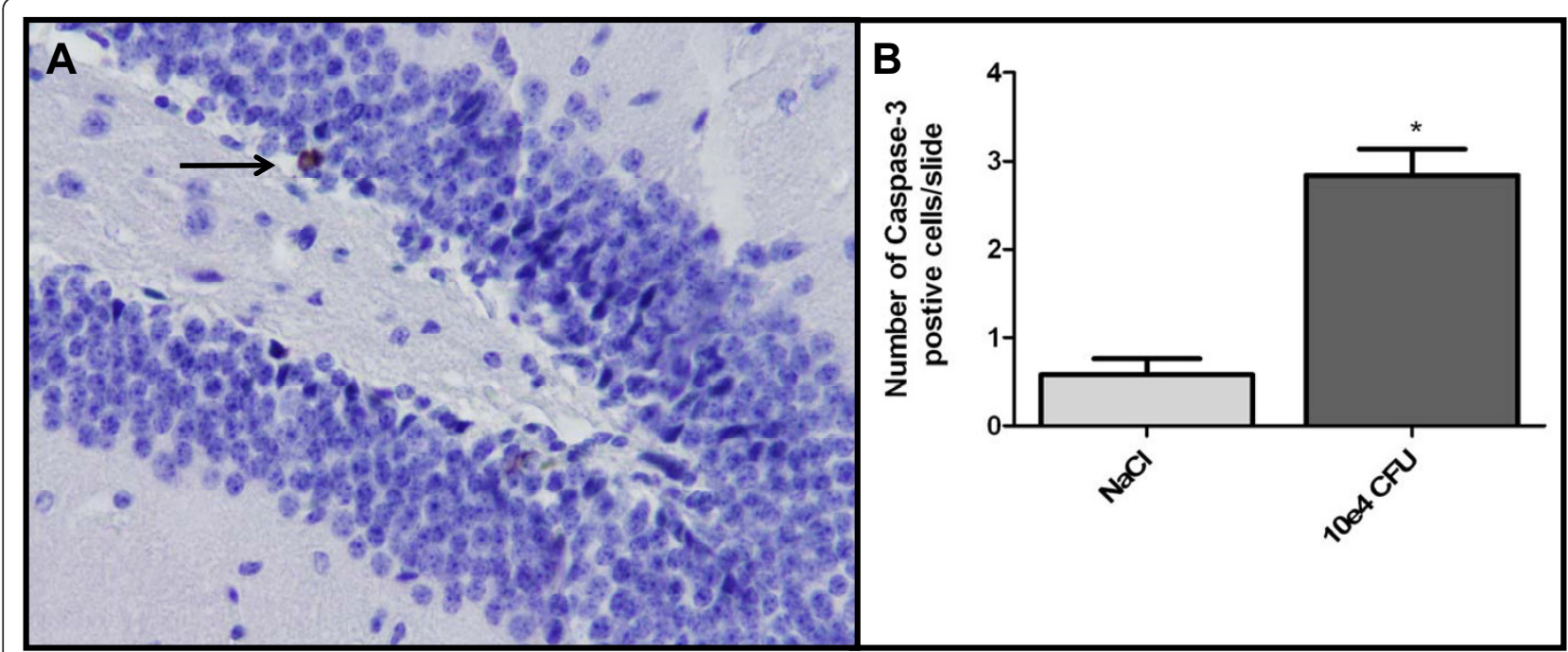

Figure 5 Neuronal apoptosis. Caspase-3 immunohistochemistry of $10 \mu \mathrm{m}$ sections of the middle portion of the hippocampus of the right cerebral hemisphere of mice inoculated with $10^{4}$ CFU S. pneumoniae at $30 \mathrm{hrs} \mathrm{post} \mathrm{infection} \mathrm{(panel} \mathrm{A;} \mathrm{200x} \mathrm{magnification).} \mathrm{Mice} \mathrm{inoculated}$ with S. pneumoniae showed significantly more hippocampal apoptosis at 30 hrs post infection than $\mathrm{NaCl}$ infected control mice (panel B, expressed in mean number of Caspase-3 positive cells/section +/- S.E.M.; groups were compared using a Student's t-test; ${ }^{*} P<0.001$ ).

and thus limited use for the study of inflammation processes, or 2) intranasal or intraperitoneal inoculation routes, which more closely models the longer physiological inflammatory mechanisms [12]. Unfortunately, mice inoculated via the intranasal or intraperitoneal route often died as the result of sepsis or pneumonia, and only $50 \%$ actually developed meningitis [17].

In this model the comparison of clinical score progression between mice with different inoculation doses lead to the following conclusions: first, although the pre-symptomatic period was dose dependent (onset of symptoms were later at lower doses of bacterial inoculation), the duration of the symptomatic period was approximately 11.5 hours and similar between groups. This dose-dependent delayed onset provides a model in which direct inoculation in the CNS results in nearly $100 \%$ of mice developing meningitis, combined with a prolonged presymptomatic period in which various inflammatory mechanisms may be studied. Second, the clinical features contributing to deterioration were largely similar between the 4 different inoculation groups. For example, at the beginning of the symptomatic period (clinical score $>10$ ) the most important contributing factors of clinical deterioration in all four inoculation groups were weight loss, diminished activity and deficits during neurological examination. At the final clinical assessment during the survival experiment, the most important additional factors of clinical deterioration in all 4 groups were the time to turn to upright position and increasing respiratory problems.

TNF- $\alpha$, IL- 1 and IL- 6 are considered to be the early response proinflammatory cytokines that are upregulated early in during pneumococcal meningitis [13]. Surprisingly, TNF- $\alpha$ was not elevated at any time-point in our model. Previous animal models demonstrated that TNF$\alpha$ was mainly increased during the first 6 to 24 hours of the immune response $[21,22]$. However, human studies show increased CSF levels of TNF- $\alpha$ but only early in the course of the disease [23,24]. This discrepancy may be explained by the lack of measurements that were performed between 6 and 30 hours after infection. IL-1 $\beta$, which in humans is increased in the first 18 hours of infection [25], was also markedly increased in brain homogenates, but not in blood in our mice 30 hours after infection. The IL- 6 concentrations did significantly increase CSF, brain homogenate and plasma 30 hours after infection. This is consistent with other infection models, in which IL-6, a cytokine displaying both proand anti-inflammatory properties [26], has been shown to be upregulated early during infection. In previous pneumococcal meningitis models IL- 6 was shown to be involved in CSF leukocyte recruitment and possibly in the regulation of blood brain barrier disruption [27]. The anti-inflammatory cytokine IL-10, which has been shown to downregulate TNF- $\alpha$, IL- 6 and $\mathrm{KC}$ was not measurably increased at any time point [28].

Of the chemokines, the functional murine IL- 8 homologue KC/CXCL1 and MIP-2/CXCL2 were both markedly increased in CSF, brain homogenate and blood at 30 hours after infection. Furthermore, early upregulation of KC and MIP-2 was also observed as early as 6 hours in brain homogenate, but not in plasma, where only $\mathrm{KC}$ was significantly increased. In humans, IL- 8 has been shown to 
be elevated in CSF during pneumococcal meningitis [29], yet in a rabbit meningitis model it was systemic IL-8 that appeared to regulate CSF pleiocytosis [30]. MIP-2, which is produced by astrocytes and microglial cells, but also by monocytes and macrophages, has been shown in vitro to be a chemoattractant for monocytes and neutrophils recruitment [29].

Brain histopathology in our model resemble the human situation in pneumococcal meningitis, We found meningeal and parenchymal infiltration, (micro)hemorrhages, perivascular lymphocitic cuffing and perivascular bacterial overgrowth, the beginning of abscess formation, microglial activation, and neuronal apoptosis in the dentate hippocampal gyrus. Parenchymal (micro)hemorrhages were frequently observed (83\%) and varied in size and location. These results reflect findings in a recent autopsy series in which microhemorrhages were found in 10 of 16 (67\%) patients who died of pneumococcal meningitis [10]. In the clinical setting clinical setting only $1-9 \%$ of all patients are documented to have intracranial hemorrhagic complications [4], which is likely to be an underestimation of the actual number of hemorrhages as only radiological evidence was included. In our model no cortical necrosis was observed at any time point, including in mice that died in the survival studies. Cerebral infarctions occur in approximately $30 \%$ of patients with pneumococcal meningitis [5,20,31], and cortical necrosis has been modeled successfully in several rat and infant mouse meningitis models [18,22]. Possible reasons for the absence of necrosis may lie in the duration from inoculation until sacrifice, the choice of animal, age of the mice used, and antibiotic treatments used in other models. The underlying mechanisms for both ischemic stroke and hemorrhages remain unclear, though human CSF studies have suggested dysregulation of local coagulation cascade, complement activation, and diffuse cerebral intravascular coagulopathy $[10,13,32]$.

The observations of microglial activation at 30 hours after infection reflect in vitro findings in which microglial cells are activated after exposure to S. pneumoniae [33]. Similarly, the delayed activation of microglial cells supports the results of a previous study in a rabbit model of pneumococcal meningitis in which increased levels of the microglial derived immunomodulatory protein activin A was found at 12 hours after inoculation [34]. Microglia represent a specific subset of cells related to monocytes and dendritic cells and form the initial line of defense of brain parenchyma against damage, injury and infection and become activated in a toll-like receptor dependent fashion upon pneumococcal exposure $[35,36]$. Upon activation, microglia produce large amounts of proinflammatory cytokines, as well as reactive oxygen and nitrogen intermediates, thereby possibly playing both neuroprotective and neurotoxic roles [13,37-39]. The role of microglia during pneumococcal meningitis is largely unknown at present, but interest has been fueled by the observation that microglial activation in vitro is limited by corticosteroids treatment [40], which has become the standard adjuvant therapy in the treatment of bacterial meningitis in many countries $[2,41]$.

Neuronal apoptosis was first observed in the human autopsy studies of patients who died of bacterial meningitis and was situated in the dentate gyrus of the hippocampus [9]. Cognitive impairments and more specifically learning difficulties have been attributed to hippocampal apoptosis which has been modeled in mice, rats and rabbits $[18,42,43]$. Furthermore, the adjuvant treatment of corticosteroids has been suggested as a possible factor aggravating hippocampal apoptosis and reducing learning capacity $[42,44]$. The process of apoptosis most likely occurs in an early caspase independent and a late caspase dependent mechanism [45]. In this model we were able to detect the late stage caspase-3 dependent apoptosis at 30 hours post infection, providing an additional outcome parameter for further pathophysiological and therapeutic investigations.

\section{Conclusions}

The value of this mouse model is that it provides an experimental setting of pneumococcal meningitis which is highly reproducible, and provides several of the most valuable outcome parameters such as bacterial titers, meningeal and parenchymal infiltration, cytokine profiles, microglial activation, neuronal apoptosis in the hippocampus, perivascular infiltration and (micro) hemorrhages. We feel that the integration of these pathological features, which are characteristic of what is observed in human autopsy studies into a single model, is a valuable tool in the further investigation of both pathophysiological and therapeutic intervention studies.

\section{Acknowledgements}

This study has been funded by grants from the European Research Council (ERC Starting Grant [Proposal/Contract no. 281156] to D. van de Beek), Netherlands Organization for Health Research and Development (ZonMw; NWO-Veni grant 2006 [Proposal/Contract no. 916.76.023], NWO-Vidi grant 2010 [Proposal/Contract no. 016.116.358] to D. van de Beek), the Academic Medical Center (AMC Fellowship 2008 to D. van de Beek).

\section{Author details}

${ }^{1}$ Department of Neurology, Center of Infection and Immunity Amsterdam (CINIMA), Academic Medical Center, Amsterdam, the Netherlands.

2Department of (Neuro) Pathology, Academic Medical Center, Amsterdam, the Netherlands. ${ }^{3}$ Center for Experimental and Molecular Medicine (CEMM), Center of Infection and Immunity Amsterdam (CINIMA), Academic Medical Center, Amsterdam, the Netherlands. ${ }^{4}$ Department of Neurology, Center of Infection and Immunity Amsterdam (CINIMA), Academic Medical Center, University of Amsterdam, P.O. Box 22660, Amsterdam 1100DD, The Netherlands. 


\section{Authors' contributions}

$\mathrm{BM}-\mathrm{K}$ and $\mathrm{MG}$ equally participated in the planning and conducting of all the herein mentioned experiments, as well as the writing of the manuscript. DT aided in the histological analyses. TP and DB conceived of the study, participated in design and execution and evaluation of the various experiments. DB provided funding and aided in the drafting of this manuscript. All authors read and approved the final manuscript.

\section{Competing interests}

The authors declare that they have no competing interests.

Received: 19 December 2011 Accepted: 28 March 2012 Published: 28 March 2012

\section{References}

1. van de Beek D, de Gans J, Spanjaard L, Weisfelt M, Reitsma JB, Vermeulen M: Clinical features and prognostic factors in adults with bacterial meningitis. N Eng/ J Med 2004, 351(18):1849-1859.

2. van de Beek D, de Gans J, Tunkel AR, Wijdicks EF: Community-acquired bacterial meningitis in adults. N Engl J Med 2006, 354(1):44-53.

3. Brouwer MC, Tunkel AR, van de Beek D: Epidemiology, diagnosis, and antimicrobial treatment of acute bacterial meningitis. Clin Microbiol Rev 2010, 23(3):467-492.

4. Weisfelt M, de Gans J, van der Poll T, van de Beek D: Pneumococcal meningitis in adults: new approaches to management and prevention. Lancet Neurol 2006, 5(4):332-342.

5. Weisfelt M, van de Beek D, Spanjaard L, Reitsma JB, de Gans J: Clinical features, complications, and outcome in adults with pneumococcal meningitis: a prospective case series. Lancet Neurol 2006, 5(2):123-129.

6. Brouwer MC, Heckenberg SG, de Gans J, Spanjaard L, Reitsma JB, van de Beek D: Nationwide implementation of adjunctive dexamethasone therapy for pneumococcal meningitis. Neurology 2010, 75:1533-1539.

7. van de Beek D, Schmand B, de Gans J, Weisfelt M, Vaessen H, Dankert J, Vermeulen M: Cognitive impairment in adults with good recovery after bacterial meningitis. J Infect Dis 2002, 186(7):1047-1052.

8. Hoogman M, van de Beek D, Weisfelt M, de Gans J, Schmand B: Cognitive outcome in adults after bacterial meningitis. I Neurol Neurosurg Psychiatry 2007, 78(10):1092-1096.

9. Nau R, Soto A, Brück W: Apoptosis of neurons in the dentate gyrus in humans suffering from bacterial meningitis. J Neuropathol Exp Neurol 1999, 58(3):265-274.

10. Vergouwen MD, Schut ES, Troost D, van de Beek D: Diffuse cerebral intravascular coagulation and cerebral infarction in pneumococcal meningitis. Neurocrit Care 2010, 13:217-227.

11. Schut ES, Brouwer MC, de Gans J, Florquin S, Troost D, van de Beek D: Delayed cerebral thrombosis after initial good recovery from pneumococcal meningitis. Neurology 2009, 73(23):1988-1995.

12. Chiavolini D, Pozzi G, Ricci S: Animal Models of Streptococcus pneumoniae Disease. Clin Microbiol Rev 2008, 21(4):666-685.

13. Mook-Kanamori BB, Geldhoff $M$, van der Poll T, van de Beek D: Pathogenesis and pathophysiology of pneumococcal meningitis. Clin Microbiol Rev 2011, 24(3):557-591.

14. Gerber J, Raivich G, Wellmer A, Noeske C, Kunst T, Werner A, Brück W, Nau R: A mouse model of Streptococcus pneumoniae meningitis mimicking several features of human disease. Acta Neuropathol 2001 101(5):499-508.

15. Quin LR, Moore QC, McDaniel LS: Pneumolysin, PspA, and PspC contribute to pneumococcal evasion of early innate immune responses during bacteremia in mice. Infect Immun 2007, 75(4):2067-2070.

16. Tan TQ, Smith CW, Hawkins EP, Mason EO, Kaplan SL: Hematogenous bacterial meningitis in an intercellular adhesion molecule-1-deficient infant mouse model. J Infect Dis 1995, 171(2):342-349.

17. Zwijnenburg PJ, Van Der Poll T, Florquin S, van Deventer SJ, Roord JJ, van Furth AM: Experimental pneumococcal meningitis in mice: a model of intranasal infection. J Infect Dis 2001, 183(7):1143-1146.

18. Grandgirard D, Steiner O, Täuber MG, Leib SL: An infant mouse model of brain damage in pneumococcal meningitis. Acta Neuropathol 2007, 114(6):609-617.

19. Koedel U, Paul R, Winkler F, Kastenbauer S, Huang PL, Pfister HW: Lack of endothelial nitric oxide synthase aggravates murine pneumococcal meningitis. J Neuropathol Exp Neurol 60(11):1041-1050.
20. Kastenbauer S, Pfister H-W: Pneumococcal meningitis in adults: spectrum of complications and prognostic factors in a series of 87 cases. Brain 2003, 126(Pt 5):1015-1025.

21. Barichello T, dos Santos I, Savi GD, Florentino AF, Silvestre C, Comim CM, Feier G, Sachs D, Teixeira MM, Teixeira AL, et al: Tumor necrosis factor alpha (TNF-alpha) levels in the brain and cerebrospinal fluid after meningitis induced by Streptococcus pneumoniae. Neurosci Lett 2009, 467(3):217-219.

22. Ostergaard C, Brandt C, Konradsen HB, Samuelsson S: Differences in survival, brain damage, and cerebrospinal fluid cytokine kinetics due to meningitis caused by 3 different Streptococcus pneumoniae serotypes: evaluation in humans and in 2 experimental models. $J$ Infect Dis 2004, 190(7):1212-1220.

23. Brivet FG, Jacobs FM, Megarbane B: Cerebral output of cytokines in patients with pneumococcal meningitis. Crit Care Med 2005, 33(11):2721-2722, author reply 2722-2723.

24. Glimaker M, Kragsbjerg P, Forsgren M, Olcen P: Tumor necrosis factoralpha (TNF alpha) in cerebrospinal fluid from patients with meningitis of different etiologies: high levels of TNF alpha indicate bacterial meningitis. J Infect Dis 1993, 167(4):882-889.

25. Schmidt H, Stuertz K, Bruck W, Chen V, Stringaris AK, Fischer FR, Nau R: Intravenous granulocyte colony-stimulating factor increases the release of tumour necrosis factor and interleukin-1beta into the cerebrospinal fluid, but does not inhibit the growth of Streptococcus pneumoniae in experimental meningitis. Scand J Immunol 1999, 49(5):481-486.

26. Gadient RA, Patterson PH: Leukemia inhibitory factor, Interleukin 6, and other cytokines using the GP130 transducing receptor: roles in inflammation and injury. Stem Cells 1999, 17(3):127-137.

27. Paul R, Koedel U, Winkler F, Kieseier BC, Fontana A, Kopf M, Hartung HP, Pfister HW: Lack of IL-6 augments inflammatory response but decreases vascular permeability in bacterial meningitis. Brain 2003, 126: $(\mathrm{Pt}$ 8):1873-1882.

28. Zwijnenburg PJG, Van Der Poll T, Florquin S, Roord JJ, van Furth AM: Interleukin-10 negatively regulates local cytokine and chemokine production but does not influence antibacterial host defense during murine pneumococcal meningitis. Infect Immun 2003, 71(4):2276-2279.

29. Spanaus KS, Nadal D, Pfister HW, Seebach J, Widmer U, Frei K, Gloor S, Fontana A: C-X-C and C-C chemokines are expressed in the cerebrospinal fluid in bacterial meningitis and mediate chemotactic activity on peripheral blood-derived polymorphonuclear and mononuclear cells in vitro. J Immunol 1997, 158(4):1956-1964.

30. Ostergaard C, Yieng-Kow RV, Larsen CG, Mukaida N, Matsushima K, Benfield T, Frimodt-Moller N, Espersen F, Kharazmi A, Lundgren JD: Treatment with a monocolonal antibody to IL-8 attenuates the pleocytosis in experimental pneumococcal meningitis in rabbits when given intravenously, but not intracisternally. Clin Exp Immunol 2000, 122(2):207-211.

31. Weststrate W, Hijdra A, de Gans J: Brain infarcts in adults with bacterial meningitis. Lancet 1996, 347(8998):399.

32. Weisfelt M, Determann RM, de Gans J, van der Ende A, Levi M, van de Beek D, Schultz MJ: Procoagulant and fibrinolytic activity in cerebrospinal fluid from adults with bacterial meningitis. J Infect 2007, 54(6):545-550

33. Liu X, Chauhan VS, Young AB, Marriott I: NOD2 mediates inflammatory responses of primary murine glia to Streptococcus pneumoniae. Glia 2010, 58(7):839-847.

34. Michel U, Gerber J, E O'Connor A, Bunkowski S, Bruck W, Nau R, Phillips DJ: Increased activin levels in cerebrospinal fluid of rabbits with bacterial meningitis are associated with activation of microglia. J Neurochem 2003, 86(1):238-245.

35. Nau R, Bruck W: Neuronal injury in bacterial meningitis: mechanisms and implications for therapy. Trends Neurosci 2002, 25(1):38-45.

36. Ribes S, Ebert S, Regen T, Agarwal A, Tauber SC, Czesnik D, Spreer A, Bunkowski S, Eiffert H, Hanisch U-K, et al: Toll-Like Receptor Stimulation Enhances Phagocytosis and Intracellular Killing of Nonencapsulated and Encapsulated Streptococcus pneumoniae by Murine Microglia. Infect Immun 2010, 78(2):865-871

37. Colton CA, Snell J, Chernyshev O, Gilbert DL: Induction of superoxide anion and nitric oxide production in cultured microglia. Ann N Y Acad Sci 1994, 738:54-63. 
38. Iliev Al, Stringaris AK, Nau R, Neumann H: Neuronal injury mediated via stimulation of microglial toll-like receptor-9 (TLR9). FASEB J 2004, 18(2):412-414

39. Marques CP, Cheeran MC, Palmquist JM, Hu S, Lokensgard JR: Microglia are the major cellular source of inducible nitric oxide synthase during experimental herpes encephalitis. J Neurovirol 2008, 14(3):229-238.

40. Hinkerohe D, Smikalla D, Schoebel A, et al: Dexamethasone prevents LPSinduced microglial activation and astroglial impairment in an experimental bacterial meningitis co-culture model. Brain Res 2010, 1329:45-54.

41. Tunkel AR, Hartman BJ, Kaplan SL, Kaufman BA, Roos KL, Scheld WM, Whitley RJ: Practice guidelines for the management of bacterial meningitis. Clin Infect Dis 2004, 39(9):1267-1284.

42. Leib SL, Heimgartner C, Bifrare Y-D, Loeffler JM, Täauber MG: Dexamethasone aggravates hippocampal apoptosis and learning deficiency in pneumococcal meningitis in infant rats. Pediatr Res 2003 54(3):353-357

43. Braun JS, Novak R, Herzog KH, Bodner SM, Cleveland JL, Tuomanen El: Neuroprotection by a caspase inhibitor in acute bacterial meningitis. Nat Med 1999, 5(3):298-302.

44. Zysk G, Bruck W, Gerber J, Bruck Y, Prange HW, Nau R: Anti-inflammatory treatment influences neuronal apoptotic cell death in the dentate gyrus in experimental pneumococcal meningitis. J Neuropathol Exp Neurol 1996, 55(6):722-728

45. Mitchell L, Smith SH, Braun JS, Herzog K-H, Weber JR, Tuomanen El: Dual phases of apoptosis in pneumococcal meningitis. J Infect Dis 2004, 190(11):2039-2046.

Pre-publication history

The pre-publication history for this paper can be accessed here: http://www.biomedcentral.com/1471-2334/12/71/prepub

doi:10.1186/1471-2334-12-71

Cite this article as: Mook-Kanamori et al.: Characterization of a pneumococcal meningitis mouse model. BMC Infectious Diseases 2012 $12: 71$.

\section{Submit your next manuscript to BioMed Central and take full advantage of:}

- Convenient online submission

- Thorough peer review

- No space constraints or color figure charges

- Immediate publication on acceptance

- Inclusion in PubMed, CAS, Scopus and Google Scholar

- Research which is freely available for redistribution

Submit your manuscript at www.biomedcentral com/submit 